\title{
Copper Distribution between FeS-Alkaline or-Alkaline Earth Metal Sulfide Fluxes and Carbon Saturated Iron Melt
}

\author{
Chao WANG, ${ }^{11}$ Tetsuya NAGASAKA, Mitsutaka HINO and Shiro BAN-YA \\ Faculty of Engineering, Tohoku University, Aza Aoba, Aramaki, Aoba-ku, Sendai, Miyagi-ken, 980 Japan. \\ 1) Research Student, Research Institute of Mineral Dressing and Metallurgy, Tohoku University, Katahira, Aoba-ku, Sendai, \\ Miyagi-ken, 980 Japan.
}

(Received on April 1, accepted in final form on July 26, 1991)

\begin{abstract}
Measurements have been made to study the effect of the addition of alkaline or alkaline earth metal sulfide such as $\mathrm{Li}_{2} \mathrm{~S}, \mathrm{~K}_{2} \mathrm{~S}, \mathrm{MgS}, \mathrm{CaS}, \mathrm{SrS}$ or BaS to $\mathrm{FeS}$ on the copper distribution ratio between FeS flux and carbon saturated liquid iron at $1673 \mathrm{~K}$. Since each solubility of $\mathrm{MgS}$ and $\mathrm{CaS}$ in liquid $\mathrm{FeS}$ was limited, no apparent effect of MgS or CaS on the copper distribution ratio was observed. Similar to the effect of $\mathrm{Na}_{2} \mathrm{~S}$ studied in our previous work, the addition of $\mathrm{Li}_{2} \mathrm{~S}, \mathrm{~K}_{2} \mathrm{~S}, \mathrm{SrS}$ or BaS to FeS increased the copper distribution ratio, $L_{\mathrm{Cu}}=(\operatorname{mass} \% \mathrm{Cu})_{\mathrm{flux}} /[\mathrm{mass} \% \mathrm{Cu}]_{\mathrm{Fe}}$ and $L_{\mathrm{Cu}}$ reached maximum value at certain content of these additives in each flux. The maximum values of $L_{c_{u}}$ measured in each flux were $30,20,22$ and 19 in $\mathrm{FeS}-\mathrm{LiS}_{0.5},-\mathrm{KS}_{0.5}, \mathrm{SrS}$ and $-\mathrm{BaS}$ fluxes, respectively. The sulfur content in liquid iron also decreased by the addition of these sulfides to FeS.
\end{abstract}

KEY WORDS: tramp element; recycling of steel scrap; alkaline metal sulfide; alkaline earth metal sulfide; copper removal; physical chemistry; steelmaking.

\section{Introduction}

The removal of copper from iron melt is necessary if recycled steel scrap is to be reutilized. ${ }^{1,2)}$ The present study focused on the process of copper removal by sulfide fluxes. ${ }^{3-10}$ ) It was hoped to reveal the thermodynamic relations existing in the process and the amount of copper it was possible to remove by this method.

As the first step, phase equilibria and thermodynamic properties of $\mathrm{Fe}-\mathrm{S}-\mathrm{C}$ ternary melt was determined as the basic system. ${ }^{11)}$ The distribution ratio of copper between $\mathrm{FeS}$ and $\mathrm{Fe}-\mathrm{C}_{\text {sat. }}$ melts, the effect of $\mathrm{NaS}_{0.5}$ on the distribution ratio and the sulfur content in iron melt was then investigated at $1673 \mathrm{~K}^{12)}$ The copper distribution ratio between sulfide flux and liquid iron, $L_{\mathrm{Cu}}$, was defined by Eq. (1).

$$
L_{\mathrm{Cu}}=(\operatorname{mass} \% \mathrm{Cu})_{\mathrm{flux}} /[\operatorname{mass} \% \mathrm{Cu}]_{\mathrm{Fe}}
$$

It was observed that copper distribution ratio $L_{\mathrm{Cu}}$ was about 9 between $\mathrm{FeS}$ and $\mathrm{Fe}-\mathrm{C}_{\text {sat. }}$. melts and increased to 24 with the addition of $\mathrm{NaS}_{0.5}$. The sulfur content in $\mathrm{Fe}-\mathrm{C}_{\text {sat. }}$ melt could be lowered to about 0.04 mass $\%$ at $X_{\mathrm{NaS}_{0.5}}=0.8$. The main reason for the increase of $L_{\mathrm{Cu}}$ is the decrease of the activity coefficient of $\mathrm{CuS}_{0.5}$ by $\mathrm{NaS}_{0.5}$ in the flux.

The alkaline metal sulfides $\mathrm{K}_{2} \mathrm{~S}$ and $\mathrm{Li}_{2} \mathrm{~S}$ are known to have physicochemical properties similar to those of $\mathrm{Na}_{2} \mathrm{~S}$. It is thus expected that usage of these alkaline metal sulfides may enhance the capacity of sulfide flux for copper removal, in spite of a lack of knowledge of the physicochemical properties of $\mathrm{FeS}-\mathrm{K}_{2} \mathrm{~S}$ and $-\mathrm{Li}_{2} \mathrm{~S}$ binaries. The effect of $\mathrm{K}_{2} \mathrm{~S}$ and $\mathrm{Li}_{2} \mathrm{~S}$ on copper distribution was therefore investigated in the present work.

The chemical properties of alkaline earth metals are similar to those of alkaline metals, so the study was also extended to their sulfides. The alkaline earth metal sulfides investigated here were $\mathrm{MgS}, \mathrm{CaS}, \mathrm{SrS}$ and $\mathrm{BaS}$, collectively referred to as MS for convenience; alkaline metal sulfides are called $\mathrm{MS}_{0.5}$.

Combined with the results using $\mathrm{Na}_{2} \mathrm{~S}$ flux, ${ }^{12)}$ a systematic analysis was done for the effects of various sulfides in FeS-based flux on copper distribution to determine the maximum copper removal possible with this process.

\section{Experimental}

The apparatus and operations were the same as described. ${ }^{12)}$ The following is a brief description of the experimental conditions.

\subsection{Materials}

Master fluxes consisted of $\mathrm{K}_{2} \mathrm{~S}$ and $\mathrm{Li}_{2} \mathrm{~S}$ of chemical reagent grade (assay: minimum $99.9 \%$ ), and $\mathrm{MgS}$, $\mathrm{CaS}, \mathrm{SrS}$ and $\mathrm{BaS}$ of guaranteed reagent grade (assay: minimum 99\%). These sulfides were respectively well mixed with an appropriate amount of iron sulfide powder to make up a predetermined composition. The mixture of $\mathrm{FeS}-\mathrm{MS}_{0.5}$ was premelted in an iron crucible, and that of FeS-MS was pressed into tablets of $10 \mathrm{~mm}$ diameter and 4 to $5 \mathrm{~g}$ in weight. The preparation of master 
$\mathrm{Fe}-\mathrm{C}$ alloy and $\mathrm{FeS}$ was the same as that given in Ref. 11).

\subsection{Procedure}

The charge consisted of about 8 to $10 \mathrm{~g}$ of each of master $\mathrm{Fe}-\mathrm{C}$ alloy and sulfide flux. Melting was done in a high frequency induction furnace. Based on the preliminary experiments, the holding time to attain equilibrium was determined as from $30 \mathrm{~min}$ to $2 \mathrm{~h}$ for the run with $\mathrm{FeS}-\mathrm{MS}_{0.5}$ flux and as 4 or $5 \mathrm{~h}$ for the run with FeS-MS flux. Following these periods, the power was turned off and the sample was quenched with a $\mathrm{He}$ jet.

\subsection{Chemical Analysis}

The analysis of contents of $\mathrm{C}, \mathrm{S}$ in metal and $\mathrm{Cu}$ in both metal and sulfide has been described. ${ }^{11,12)} \mathrm{K}$ and $\mathrm{Li}$ in sulfides were determined by atomic absorption spectroscopy. The contents of alkaline earth metals, i.e. $\mathrm{Mg}, \mathrm{Ca}, \mathrm{Sr}$ and $\mathrm{Ba}$, in sulfides were analyzed by Inductively Coupled Plasma spectroscopy (ICP).

\section{Results}

Experimental results are shown in Table 1. Similar to the findings in Ref. 12), sulfide contents are defined by cationic fraction.

\subsection{Effect of Alkaline Metal Sulfides on Copper Dis- tribution}

The increase of $L_{\mathrm{Cu}}$ by $\mathrm{NaS}_{0.5}$ was found to be hindered if the content of $\mathrm{CuS}_{0.5}$ was high in the flux. ${ }^{12)}$ Thus this investigation was carried out on two content levels of $X_{\mathrm{CuS}_{0.5}}$, one of which was below 0.01 and the other from 0.01 to 0.05 .

\subsubsection{Effect of Flux Composition on $L_{\mathrm{Cu}}$}

Effects of contents of $\mathrm{KS}_{0.5}$ and $\mathrm{LiS}_{0.5}$ in the flux on copper distribution ratio between $\mathrm{FeS}-\mathrm{MS}_{0.5}$ flux and carbon saturated iron melt are presented in Figs. 1(a)

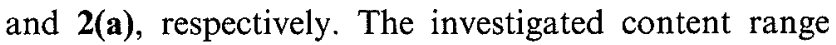
of $\mathrm{KS}_{0.5}$ was within $X_{\mathrm{KS}_{0.5}}=0.55$ because of its high vapor pressure at $1673 \mathrm{~K}$.

Figures 1(a) and 2(a) show that copper distribution ratio increases with increasing content of either $\mathrm{KS}_{0.5}$ or $\mathrm{LiS}_{0.5}$ in flux and reaches a maximum of 20 at about $X_{\mathrm{KS}_{0.5}}=0.3$ for $\mathrm{FeS}-\mathrm{KS}_{0.5}$ flux and 30 at $X_{\mathrm{LiS}_{0.5}}=0.6$ for $\mathrm{FeS}-\mathrm{LiS}_{0.5}$ flux. That is, the addition of $\mathrm{KS}_{0.5}$ and $\mathrm{LiS}_{0.5}$ into FeS has the similar effect on $L_{\mathrm{Cu}}$ with that of $\mathrm{NaS}_{0.5}$ which increases copper distribution ratio. Also, further increase in $\mathrm{MS}_{0.5}$ content tends to lower $L_{\mathrm{Cu}}$ slightly after the maximum of $L_{\mathrm{Cu}}$. The data of Imai and Sano ${ }^{9,13)}$ at $1473 \mathrm{~K}$ are also given in Fig. 1, and appear in agreement with the present work.

The effect of $\mathrm{CuS}_{0.5}$ content in FeS-LiS ${ }_{0.5}$ flux on $L_{\mathrm{Cu}}$ shows the same tendency as that in $\mathrm{FeS}-\mathrm{NaS}_{0.5}$ flux. That is, a high content of $\mathrm{CuS}_{0.5}$ in flux tends to lower copper distribution ratio in the high content range of $\mathrm{LiS}_{0.5}$. On the other hand, no measurable effect of $\mathrm{CuS}_{0.5}$ in $\mathrm{FeS}-\mathrm{KS}_{0.5}$ flux on $L_{\mathrm{Cu}}$ is seen in Fig. 1(a), which may be due to the limited composition range in both $\mathrm{KS}_{0.5}$ and $\mathrm{CuS}_{0.5}$.

Figure 3 gives a comparison among the effects of
Table 1. Experimental results of copper distribution between $\mathrm{FeS}-\mathrm{MS}_{\mathbf{x}}(\mathrm{M}: \mathrm{K}, \mathrm{Li}, \mathrm{Mg}, \mathrm{Ca}, \mathrm{Sr}, \mathrm{Ba}$ ) flux and carbon saturated liquid iron at $1673 \mathrm{~K}$.

\begin{tabular}{|c|c|c|c|c|c|c|c|}
\hline \multirow{2}{*}{$\begin{array}{l}\text { Run } \\
\text { No. }\end{array}$} & \multicolumn{3}{|c|}{ Iron phase } & \multicolumn{3}{|c|}{ Flux phase } & \multirow{2}{*}{$\mathrm{L}_{\mathrm{Cu}}$} \\
\hline & {$[\% \mathrm{Cu}]$} & {$[\% \mathrm{~S}]$} & {$[\% \mathrm{C}]$} & $(\% \mathrm{Cu})$ & $(\% \mathrm{Fe})$ & $(\% \mathrm{M})$ & \\
\hline \multicolumn{8}{|c|}{$\mathrm{FeS}-\mathrm{K}_{2} \mathrm{~S}$} \\
\hline$K-6$ & 0.058 & 0.53 & $4.7 !$ & 1.07 & 41.66 & 24.34 & 18.45 \\
\hline $\mathrm{K}-7$ & 0.048 & 0.93 & 4.58 & 0.93 & 50.66 & 17.02 & 19.38 \\
\hline $\mathbf{K}-8$ & 0.054 & 1.13 & 4.51 & 0.96 & 59.15 & 10.10 & 17.78 \\
\hline K- 9 & 0.057 & 1.45 & 4.41 & 0.84 & 67.64 & 3.58 & 14.74 \\
\hline $\mathrm{K}-11$ & 0.050 & 0.60 & 4.69 & 0.99 & 45.92 & 20.48 & 19.80 \\
\hline $\mathrm{K}-12$ & 0.053 & 0.73 & 4.64 & 1.01 & 50.50 & 16.00 & 19.06 \\
\hline $\mathrm{K}-13$ & 0.052 & 0.82 & 4.61 & 1.05 & 48.83 & 18.39 & 20.19 \\
\hline $\mathrm{K}-15$ & 0.046 & 0.35 & 4.77 & 0.83 & 35.67 & 30.33 & 18.04 \\
\hline $\mathrm{K}-16$ & 0.19 & 0.88 & 4.58 & 3.89 & 46.56 & 15.70 & 20.47 \\
\hline $\mathrm{K}-17$ & 0.25 & 1.12 & 4.50 & 4.84 & 49.33 & 13.91 & 19.36 \\
\hline $\mathrm{K}-18$ & 0.31 & 1.25 & 4.45 & 5.54 & 51.59 & 10.50 & 17.87 \\
\hline $\mathrm{K}-\mathrm{I} 9$ & 0.25 & 1.23 & 4.46 & 4.39 & 55.91 & 7.23 & 17.56 \\
\hline $\mathrm{K}-20$ & 0.37 & 1.38 & 4.40 & 5.58 & 60.53 & 3.12 & 15.08 \\
\hline K-22 & 0.24 & 0.63 & 4.66 & 4.56 & 40.55 & 23.34 & 19.00 \\
\hline $\mathrm{K}-23$ & 0.25 & 0.65 & 4.65 & 4.98 & 40.85 & 19.27 & 19.92 \\
\hline $\mathrm{K}-24$ & 0.25 & 0.37 & 4.75 & 4.27 & 35.10 & 25.96 & 17.08 \\
\hline $\mathrm{K}-25$ & 0.35 & 0.83 & 4.58 & 6.93 & 43.62 & 14.50 & 19.80 \\
\hline $\mathrm{K}-26$ & 0.22 & 1.02 & 4.53 & 4.48 & 49.16 & 11.77 & 20.36 \\
\hline $\mathrm{K}-27$ & 0.26 & I. 19 & 4.47 & 4.66 & 53.19 & 8.84 & 17.92 \\
\hline
\end{tabular}

\section{$\mathrm{FeS}-\mathrm{Li}_{2} \mathrm{~S}$}

\begin{tabular}{l|rrr|rrr|r}
\hline Li- 7 & 0.026 & 1.55 & 4.38 & 0.35 & 57.21 & 3.42 & 13.46 \\
Li- 8 & 0.034 & 1.86 & 4.27 & 0.39 & 61.32 & 2.29 & 11.56 \\
Li- 9 & 0.028 & 1.84 & 4.28 & 0.29 & 64.76 & 1.33 & 10.39 \\
$\mathrm{Li}-10$ & 0.033 & 0.15 & 4.84 & 0.95 & 34.98 & 13.98 & 28.70 \\
$\mathrm{Li}-11$ & 0.027 & 0.28 & 4.80 & 0.86 & 46.14 & 9.64 & 31.85 \\
$\mathrm{Li}-12$ & 0.030 & 0.26 & 4.80 & 0.89 & 45.26 & 9.79 & 29.67 \\
$\mathrm{Li}-13$ & 0.079 & 1.63 & 4.34 & 0.98 & 61.41 & 3.19 & 12.41 \\
$\mathrm{Li}-14$ & 0.096 & 1.97 & 4.23 & 0.95 & 64.64 & 1.92 & 9.90 \\
$\mathrm{Li}-15$ & 0.081 & 2.05 & 4.21 & 0.92 & 69.90 & 1.04 & 11.36 \\
$\mathrm{Li}-16$ & 0.029 & 0.44 & 4.74 & 0.88 & 48.30 & 7.09 & 30.35 \\
$\mathrm{Li}-17$ & 0.028 & 0.60 & 4.69 & 0.78 & 50.14 & 6.08 & 27.86 \\
$\mathrm{Li}-18$ & 0.058 & 1.19 & 4.49 & 0.85 & 55.83 & 4.72 & 14.66 \\
$\mathrm{Li}-19$ & 0.277 & 0.11 & 4.83 & 6.02 & 27.74 & 15.11 & 21.74 \\
$\mathrm{Li}-20$ & 0.224 & 0.21 & 4.80 & 5.59 & 33.27 & 11.86 & 24.94 \\
$\mathrm{Li}-21$ & 0.210 & 0.34 & 4.76 & 5.43 & 39.42 & 9.03 & 25.88 \\
$\mathrm{Li}-22$ & 0.206 & 0.50 & 4.71 & 5.81 & 42.18 & 7.78 & 28.20 \\
$\mathrm{Li}-23$ & 0.321 & 1.07 & 4.51 & 5.22 & 45.20 & 5.22 & 16.26 \\
$\mathrm{Li}-24$ & 0.469 & 1.88 & 4.23 & 5.35 & 53.70 & 3.23 & 11.40 \\
$\mathrm{Li}-26$ & 0.207 & 0.62 & 4.67 & 5.35 & 44.98 & 6.11 & 25.86 \\
$\mathrm{Li}-27$ & 0.338 & 1.30 & 4.43 & 5.49 & 48.98 & 4.74 & 16.25 \\
$\mathrm{Li}-28$ & 0.556 & 1.49 & 4.35 & 5.59 & 54.68 & 2.79 & 10.06 \\
\hline
\end{tabular}

FeS-MgS

\begin{tabular}{l|lll|lll|l}
\hline Mg- 2 & 0.136 & 1.52 & 4.38 & 1.15 & 64.21 & 2.90 & 8.46 \\
Mg- 3 & 0.098 & 1.65 & 4.34 & 0.94 & 67.72 & 1.13 & 9.57 \\
Mg-5 & 0.071 & 1.27 & 4.46 & 0.59 & 62.40 & 3.76 & 8.27 \\
Mg-10 & 0.038 & 1.42 & 4.42 & 0.38 & 63.33 & 3.25 & 9.90 \\
\hline
\end{tabular}

\section{$\mathrm{FeS}-\mathrm{CaS}$}

\begin{tabular}{l|rll|lll|r}
\hline $\mathrm{Ca}-4$ & 0.088 & 1.14 & 4.51 & 0.77 & 58.33 & 7.82 & 8.75 \\
$\mathrm{Ca}-6$ & 0.033 & 1.66 & 4.35 & 0.30 & 63.75 & 4.15 & 8.94 \\
$\mathrm{Ca}-7$ & 0.072 & 1.46 & 4.41 & 0.67 & 62.04 & 4.45 & 9.31 \\
$\mathrm{Ca}-9$ & 0.035 & 1.22 & 4.48 & 0.36 & 58.34 & 6.50 & 10.17 \\
\hline
\end{tabular}

$\mathrm{FeS}-\mathrm{SrS}$

\begin{tabular}{r|rrr|rrr|r}
\hline Sr- 1 & 0.070 & 1.52 & 4.38 & 0.83 & 56.66 & 10.47 & 11.86 \\
Sr- 2 & 0.069 & 1.39 & 4.43 & 0.74 & 61.63 & 6.39 & 10.73 \\
Sr- 3 & 0.067 & 1.78 & 4.30 & 0.70 & 66.39 & 3.03 & 10.45 \\
Sr- 4 & 0.042 & 1.24 & 4.48 & 0.63 & 48.37 & 18.83 & 15.00 \\
Sr- 7 & 0.027 & 0.75 & 4.65 & 0.60 & 42.00 & 24.53 & 22.22 \\
\hline
\end{tabular}

\section{FeS-BaS}

\begin{tabular}{l|rll|llr|r}
\hline $\mathrm{Ba}-1$ & 0.044 & 1.64 & 4.34 & 0.49 & 66.82 & 3.22 & 11.14 \\
$\mathrm{Ba}-2$ & 0.012 & 1.73 & 4.32 & 0.11 & 63.91 & 7.08 & 9.50 \\
$\mathrm{Ba}-3$ & 0.009 & 1.65 & 4.34 & 0.10 & 58.92 & 10.97 & 10.67 \\
$\mathrm{Ba}-4$ & 0.029 & 1.08 & 4.53 & 0.49 & 43.47 & 25.74 & 16.79 \\
$\mathrm{Ba}-6$ & 0.026 & 0.67 & 4.67 & 0.54 & 36.56 & 33.71 & 20.65 \\
$\mathrm{Ba}-9$ & 0.065 & 0.49 & 4.72 & 1.16 & 30.41 & 39.99 & 17.85 \\
$\mathrm{Ba}-10$ & 0.052 & 0.45 & 4.74 & 0.97 & 29.60 & 41.13 & 18.65 \\
$\mathrm{Ba}-12$ & 0.087 & 0.56 & 4.74 & 1.57 & 32.13 & 37.96 & 18.05 \\
$\mathrm{Ba}-13$ & 0.084 & 0.61 & 4.68 & 1.64 & 34.89 & 34.23 & 19.52 \\
$\mathrm{Ba}-14$ & 0.097 & 0.87 & 4.59 & 1.66 & 41.83 & 27.76 & 17.11 \\
\hline
\end{tabular}

Concentrations are in mass $\%$. 

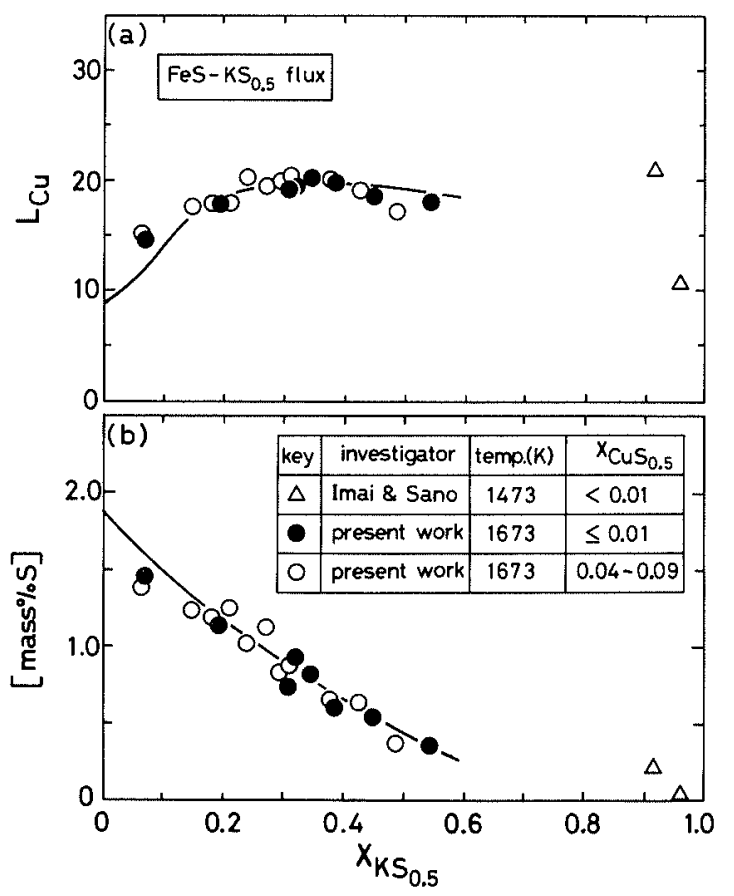

Fig. 1. Variations of (a) $L_{\mathrm{Cu}}$ and (b) sulfur content in carbon saturated liquid iron with $\mathrm{KS}_{0.5}$ content in $\mathrm{FeS}-\mathrm{KS}_{0.5}$ flux.
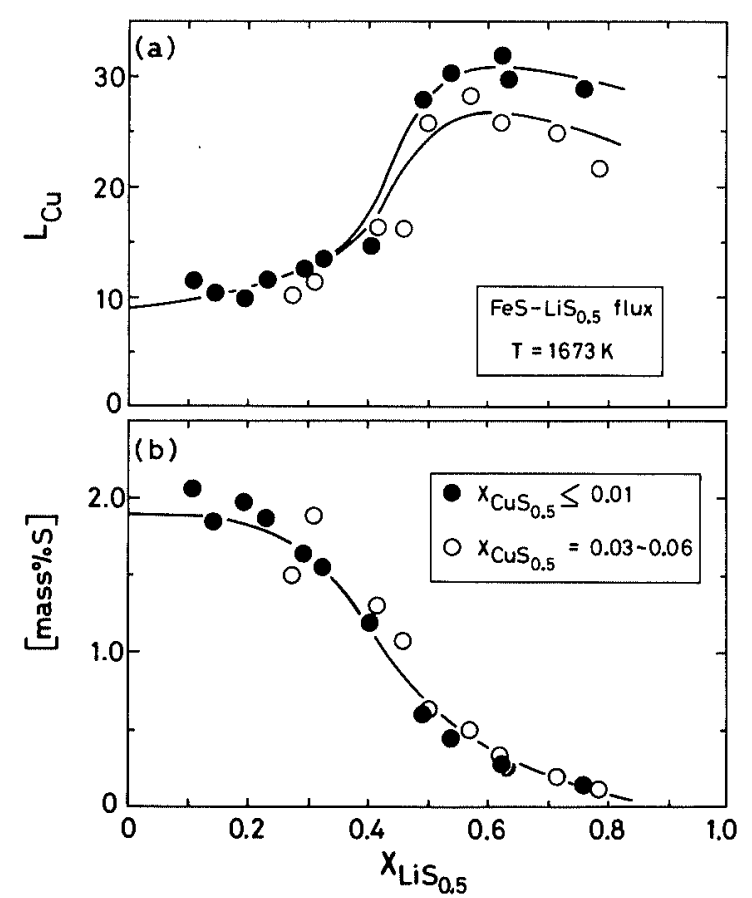

Fig. 2. Variations of (a) $L_{\mathrm{Cu}}$ and (b) sulfur content in carbon saturated liquid iron with $\mathrm{LiS}_{0.5}$ content in $\mathrm{FeS}-\mathrm{LiS}_{0.5}$ flux.

$\mathrm{KS}_{0.5}, \mathrm{NaS}_{0.5}$ and $\mathrm{LiS}_{0.5}$ on $L_{\mathrm{Cu}}$. The data of $X_{\mathrm{CuS}_{0.5}}<$ 0.02 are shown here in order to approach the practical condition. Acordingly, the increasing magnitude of $L_{\mathrm{Cu}}$ is larger in the order of $\mathrm{LiS}_{0.5}, \mathrm{NaS}_{0.5}$ and $\mathrm{KS}_{0.5}$ in the composition range below that corresponding to the maximum of $L_{\mathrm{Cu}}$ : at a given low content of $\mathrm{MS}_{0.5}$, the larger the atomic number of the cationic species is, the greater the increasing magnitude of $L_{\mathrm{Cu}}$ is. On the other side, the maximum of $L_{\mathrm{Cu}}$ is larger in a sequence of $\mathrm{KS}_{0.5}, \mathrm{NaS}_{0.5}$ and $\mathrm{LiS}_{0.5}$ with values of about 20,24

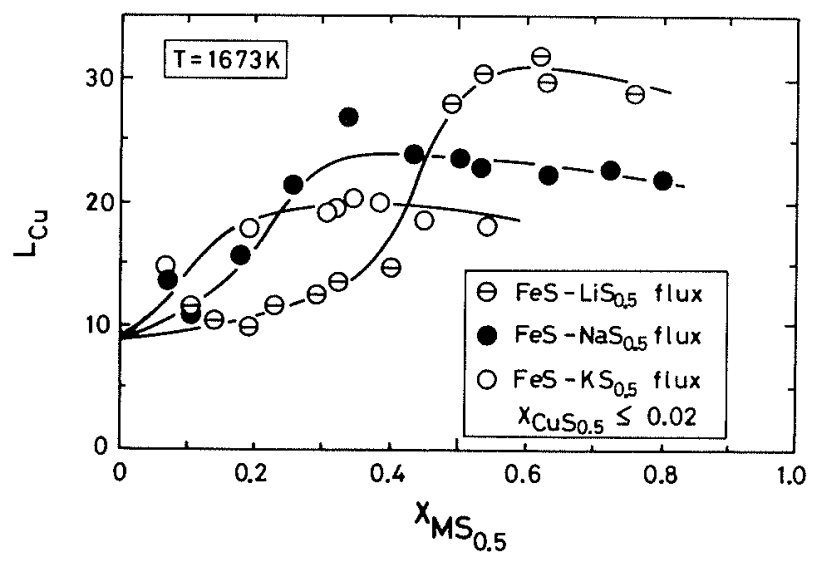

Fig. 3. Effect of alkaline metal sulfide, $\mathrm{MS}_{0.5}$, on $L_{\mathrm{Cu}}$ in $\mathrm{FeS}-\mathrm{MS}_{0.5}$ fluxes.

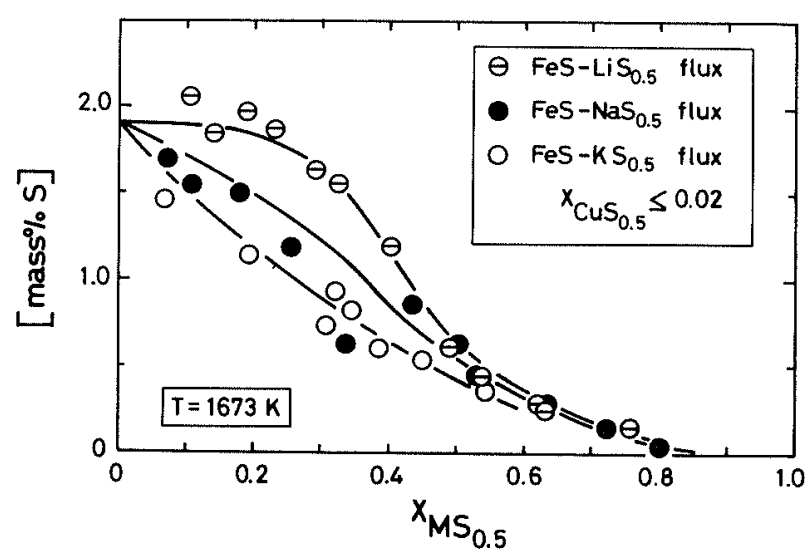

Fig. 4. Effect of $\mathrm{MS}_{0.5}$ on sulfur content in carbon saturated liquid iron in $\mathrm{FeS}-\mathrm{MS}_{0.5}$ fluxes.

and 30 , respectively. That is, the maximum of $L_{\mathrm{Cu}}$ is larger at a smaller atomic number of $M$, the cationic species. Consequently, the content of $\mathrm{MS}_{0.5}$ corresponding to the maximum of $L_{\mathrm{Cu}}$ is higher in a sequence of $\mathrm{KS}_{0.5}, \mathrm{NaS}_{0.5}$ and $\mathrm{LiS}_{0.5}$.

\subsubsection{Effect of Flux Composition on Sulfur Content} in $\mathrm{Fe}-\mathrm{C}_{\text {sat. }}$ Melt

A higher sulfur potential in the system is expected to enhance the copper removal because of the greater sulfurization reaction. On the other hand, as a detrimental impurity in steel sulfur content should normally be lowered as much as possible. Figures 1(b) and 2(b) show, respectively, the relations between the equilibrium sulfur content in $\mathrm{Fe}-\mathrm{C}_{\text {sat. }}$ melt and the content of $\mathrm{KS}_{0.5}$ or $\mathrm{LiS}_{0.5}$ in flux at different levels of $\mathrm{CuS}_{0.5}$. It is seen that the sulfur content in $\mathrm{Fe}-\mathrm{C}_{\text {sat. }}$ melt decreases markedly with increasing $\mathrm{MS}_{0.5}$ content in FeS-based flux. For example, [mass $\% \mathrm{~S}]$ decreases from about 1.9 at $X_{\mathrm{MS}_{0.5}}=0$ to about 0.1 at $X_{\mathrm{LiS}_{\text {o. }}}=0.75$.

The influence of $\mathrm{CuS}_{0.5}$ in the flux on the sulfur content in $\mathrm{Fe}-\mathrm{C}_{\text {sat. }}$ melt does not seem to be clear for the fluxes of $\mathrm{FeS}-\mathrm{KS}_{0.5}$ and $-\mathrm{LiS}_{0.5}$ under the present experimental conditions.

Figure 4 shows the relation between sulfur content and the content of $\mathrm{MS}_{0.5}$ in FeS-MS ${ }_{0.5}$ fluxes, including the data with $\mathrm{NaS}_{0.5}$ reported in Ref. 12). The concentration of $\mathrm{CuS}_{0.5}$ in Fig. 4 is less than 0.02 mole fraction. Accordingly, at a given content of $\mathrm{MS}_{0.5}$, the sulfur 
content is the lowest by $\mathrm{KS}_{0.5}$, followed by $\mathrm{NaS}_{0.5}$ and $\mathrm{LiS}_{0.5}$ in this order. However, the difference in sulfur content with these three fluxes tends to be negligible with increasing content of $\mathrm{MS}_{0.5}$.

Based on the above results and those with $\mathrm{FeS}-\mathrm{NaS}_{0.5}$ flux, ${ }^{12)}$ it is concluded that the alkaline metal sulfides are effective in both increasing copper distribution ratio and reducing the sulfur content in $\mathrm{Fe}-\mathrm{C}_{\text {sat. }}$ melt. As presented in Fig. 3, though $L_{\mathrm{Cu}}$ tends to decrease slightly with greater $\mathrm{MS}_{0.5}$ content after the maximum of $L_{\mathrm{Cu}}$, this decrease is essentially insignificant. In contrast, Fig. 4 shows the sulfur content in $\mathrm{Fe}-\mathrm{C}_{\text {sat. }}$ decreases monotonously with increasing $\mathrm{MS}_{0.5}$ content. Therefore, it is better to select a flux of high $\mathrm{MS}_{0.5}$ content, e.g. $X_{\mathrm{MS}_{0.5}}=0.7$ to 0.8 , so that it is possible to obtain a $L_{\mathrm{Cu}}$ between 20 and 30 with [mass $\% \mathrm{~S}$ ] in iron below 0.1 .

\subsection{Effect of Alkaline Earth Metal Sulfides on Cop- per Distribution}

The content of $\mathrm{CuS}_{0.5}$ was adjusted to below 0.03 mole fraction for this part of the experiments in view of practical usage.

\subsubsection{Effect of Flux Composition on $L_{\mathrm{Cu}}$}

MS generally has high melting points above $2300 \mathrm{~K},{ }^{14}$ ) thus, its solubility in molten FeS at $1673 \mathrm{~K}$ must be limited. However, there is little information on the phase diagram of FeS-MS binaries or the solubility of MS in molten FeS around $1673 \mathrm{~K}$. The solubilities of $\mathrm{MgS}$, $\mathrm{CaS}, \mathrm{SrS}$ and $\mathrm{BaS}$ were therefore estimated experimentally in the present work, as shown in the Appendix.

Figure 5 shows the relation between $L_{\mathrm{Cu}}$ and $X_{\mathrm{MS}}$ in FeS-MS fluxes. The addition of MgS and $\mathrm{CaS}$ to molten FeS seems to have little effect on $L_{\mathrm{Cu}}$, but it is difficult to fully define the effect of these sulfides on $L_{\mathrm{Cu}}$ from the available data because of the very limited homogeneous liquid range.

$L_{\mathrm{Cu}}$ does, however, obviously increase with increasing $\mathrm{SrS}$ or BaS content in molten $\mathrm{FeS}$, its maximum value being about 22 with near saturation of SrS. The variation of $L_{\mathrm{Cu}}$ against $X_{\mathrm{BaS}}$ in the flux appears very close to that with $\mathrm{FeS}-\mathrm{MS}_{0.5}$ fluxes. $L_{\mathrm{Cu}}$ increases with increasing $X_{\mathrm{BaS}}$ when $\mathrm{BaS}$ content is low and becomes maximum of about 19 around $X_{\mathrm{BaS}}=0.25$ until BaS saturation. These data indicate that the maximums of $L_{\mathrm{Cu}}$ with $\mathrm{FeS}-\mathrm{SrS}$ and $-\mathrm{BaS}$ fluxes are nearly equivalent to those

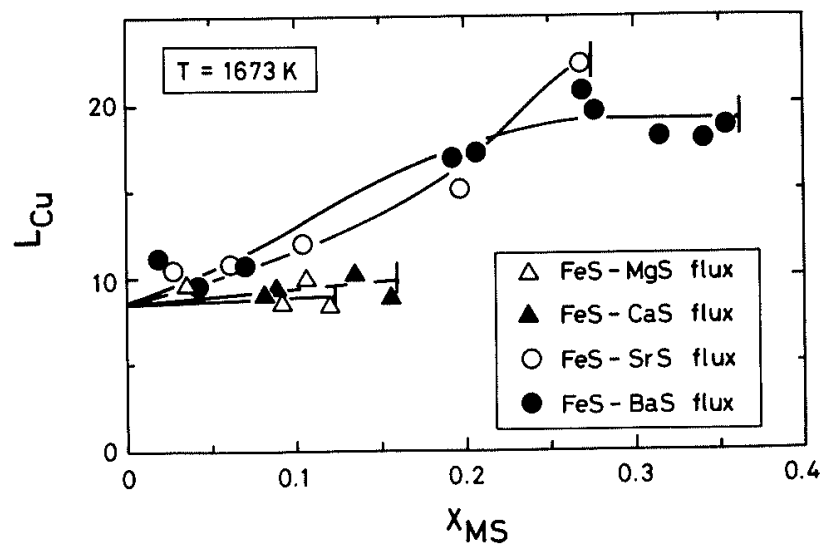

Fig. 5. Effect of alkaline earth metal sulfide, $M S$, on $L_{\mathrm{Cu}}$ in FeS-MS fluxes. with $\mathrm{FeS}-\mathrm{MS}_{0.5}$ fluxes.

It is noticed from Fig. 5 that the increase of $L_{\mathrm{Cu}}$ by MS is larger in the order of $\mathrm{MgS}, \mathrm{CaS}, \mathrm{SrS}$ and $\mathrm{BaS}$ at a given content of $\mathrm{MS}$ in the low range, i.e. the larger the atomic number of $M$ is, the greater the value of $L_{\mathrm{Cu}}$ is. However, the maximum of $L_{\mathrm{Cu}}$ becomes larger with $\mathrm{FeS}-\mathrm{SrS}$ flux than with FeS-BaS, i.e. the smaller atomic number of $M$ leads to a larger value for the maximum of $L_{\mathrm{Cu}}$. This tendency is coincident with that observed in the fluxes of $\mathrm{FeS}-\mathrm{MS}_{0.5}$. It suggests that the effect of $\mathrm{MS}_{0.5}$ and $\mathrm{MS}$ in the flux on $L_{\mathrm{Cu}}$ may chemically be the same, though the investigated composition range is limited for FeS-MS system.

\subsubsection{Effect of the Composition of FeS-MS Flux on the Sulfur Content in $\mathrm{Fe}-\mathrm{C}_{\text {sat. }}$ Melt}

Figure 6 shows the relation between the sulfur content in $\mathrm{Fe}-\mathrm{C}_{\text {sat. }}$ melt and the concentration of MS in the fluxes. The sulfur content decreases monotonously with increasing content of any MS in the flux and becomes a certain value after MS saturation. Also as shown, the difference in sulfur content is negligible at a given MS concentration for four FeS-MS fluxes within the homogeneous liquid range of fluxes. This means that the effects of the four sulfides on the activity of $\mathrm{FeS}$ in the flux are the same.

\subsection{Copper Distribution Ratio in Mole Fraction}

The molecular weights of $\mathrm{MS}_{0.5}$ and MS ranged widely

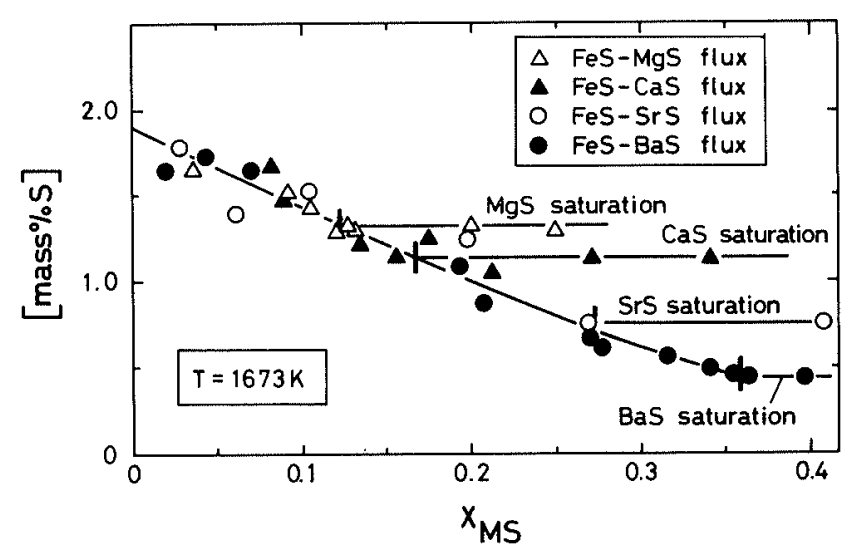

Fig. 6. Effect of MS on sulfur content in carbon saturated liquid iron in FeS-MS fluxes.

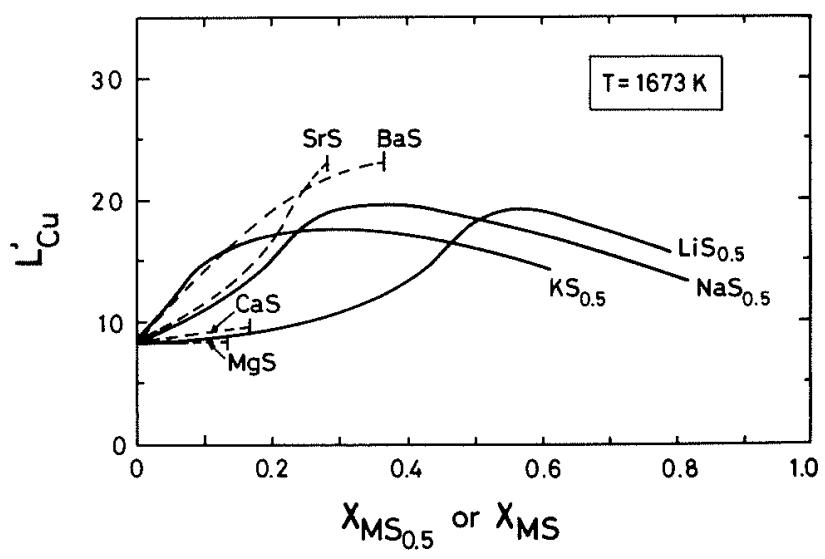

Fig. 7. Effect of $\mathrm{MS}_{0.5}$ or MS on the molar distribution ratio of copper, $L_{\mathrm{Cu}}^{\prime}$, in FeS-MS $\mathrm{M}_{0.5}$ and FeS-MS fluxes. 
in the present work. For example, the molecular weight of $\mathrm{LiS}_{0.5}$ was only 22.97 while that of $\mathrm{BaS}$ was about 6 times larger at 169.40 . Thus the distribution ratio of copper is defined in mole fraction as Eq. (2), and this equation can also reevaluate the results presented in Figs. 3 and 5.

$$
L_{\mathrm{Cu}}^{\prime}=(\mathrm{mol} \% \mathrm{Cu})_{\mathrm{flux}} /[\mathrm{mol} \% \mathrm{Cu}]_{\mathrm{Fe}}
$$

Figure 7 shows the relation between $L_{\mathrm{Cu}}^{\prime}$ and the content of $\mathrm{MS}_{0.5}$ and MS in fluxes. Compared with Figs. 3 and 5, the distribution ratio of copper becomes relatively larger in $L_{\mathrm{Cu}}^{\prime}$ for the flux containing a sulfide of large molecular weight such as $\mathrm{SrS}$ or BaS. On the contrary, $L_{\mathrm{Cu}}^{\prime}$ for the flux containing $\mathrm{LiS}_{0.5}$ which has the smallest molecular weight becomes relatively smaller. As a result, the maximum of $L_{\mathrm{Cu}}^{\prime}$ with FeS-SrS or FeS-BaS flux becomes the largest, while the maximums with FeS- $\mathrm{MS}_{0.5}$ fluxes are about the same and slightly lower than that with FeS-SrS or FeS-BaS flux.

\section{Discussion}

\subsection{Effect of Alkaline and Alkaline Earth Metal Sul- fides on the Activity of $\mathrm{FeS}$ in the Fluxes}

The reaction of copper removal and that between iron and sulfur are given by Eqs. (3) an (5), respectively.

$$
\begin{aligned}
& \underline{\mathrm{Cu}}+1 / 2 \underline{\mathrm{S}}=\mathrm{CuS}_{0.5}(1) \\
& K_{3}=a_{\mathrm{CuS}_{0.5}} /\left(a_{\underline{\mathrm{Cu}}} a_{\underline{\mathrm{S}}}^{1 / 2}\right) \\
& \mathrm{Fe}(1)+\underline{\mathrm{S}}=\mathrm{FeS}(\mathrm{l}) \ldots . . \\
& K_{5}=a_{\mathrm{FeS}} /\left(a_{\mathrm{Fe}} a_{\underline{\mathrm{S}}}\right) \ldots \ldots . .
\end{aligned}
$$

From Eqs. (1), (3) and (5), the distribution ratio of copper between flux and iron melt may be written as Eq. $(7)^{12)}$ as

$$
L_{\mathrm{Cu}}=C^{\prime} \gamma_{\underline{\mathrm{Cu}}} a_{\mathrm{FeS}}^{1 / 2} / \gamma_{\mathrm{CuS}_{\mathrm{o} .5}}
$$

where $C^{\prime}$ is about a constant. The value of $\gamma_{\mathrm{Cu}}$, depending on the composition of $\mathrm{Fe}-\mathrm{C}_{\text {sat. }}$ melt, is about constant under the present condition. ${ }^{12)}$ Hence, $L_{\mathrm{Cu}}$ may be expressed as a function of $a_{\mathrm{FeS}}$ and $\gamma_{\mathrm{CuS}_{0.5}}$ which depend on flux composition. That is, it is necessary to reveal the variation of these two thermodynamic quantities for full understanding of the effect of flux composition on copper

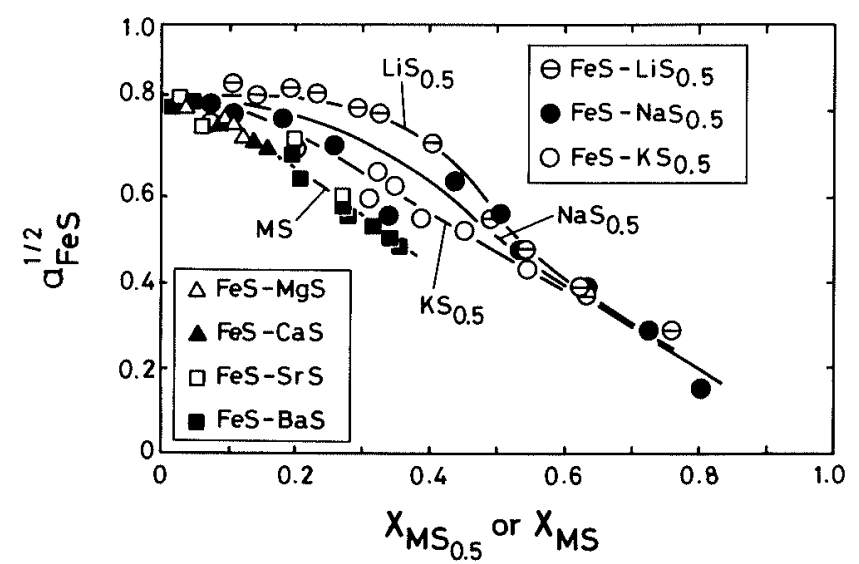

Fig. 8. Effect of $\mathrm{MS}_{0.5}$ or $\mathrm{MS}$ on $a_{\mathrm{FcS}}^{1 / 2}$ in FeS-MS $\mathrm{MS}_{0.5}$ fluxes. distribution.

The expression for $a_{\mathrm{FeS}}$ may be written as Eq. (8) from Eq. (6):

$$
a_{\mathrm{FeS}}=K_{5} a_{\mathrm{Fe}} a_{\mathrm{S}}
$$

As $a_{\mathrm{Fe}}, a_{\mathrm{S}}$ and $K_{5}$ are available from Refs. 11) and 12), the activity of FeS can be evaluated using Eq. (8).

Figure 8 shows the relation of $a_{\mathrm{FeS}}^{1 / 2}$ to the contents of various $\mathrm{MS}_{0.5}$ and $\mathrm{MS}$ in fluxes. Generally, $a_{\mathrm{FeS}}^{1 / 2}$ decreases monotonously with increasing $\mathrm{MS}_{0.5}$ content. But comparatively, among alkaline metal sulfides, $\mathrm{KS}_{0.5}$ seems to be the most effective in decreasing $a_{\mathrm{FeS}}^{1 / 2}$, followed by $\mathrm{NaS}_{0.5}$. However, no measurable difference is observed between $a_{\mathrm{FeS}}^{1 / 2}$ and $X_{\mathrm{MS}_{0.5}}$ for three kinds of fluxes when $X_{\mathrm{MS}_{0.5}}$ exceeds 0.5 . The effect of MS on $a_{\mathrm{FeS}}^{1 / 2}$ is considered to be equivalent according to Fig. 8 .

\subsection{Effects of $\mathbf{M S}_{0.5}$ and $\mathrm{MS}$ in Fluxes on $\gamma_{\mathrm{CuS}_{0.5}}$}

The activity coefficient of $\mathrm{CuS}_{0.5}$ may be written as Eq. (9) from Eq. (4).

$$
\gamma_{\mathrm{CuS}_{0.5}}=K_{3} a_{\underline{\mathrm{Cu}}} a_{\underline{\mathrm{S}}}^{1 / 2} / X_{\mathrm{CuS}_{0.5}}
$$

Accordingly, $\gamma_{\text {CuS }_{0.5}}$ may be evaluated from Eq. (9). ${ }^{12)}$ Figures 9 and 10 present the relations of $\gamma_{\mathrm{CuS}_{0.5}}$ to the contents of $\mathrm{MS}_{0.5}$ and $\mathrm{MS}$ in fluxes, respectively. At a given content of $X_{\mathrm{MS}_{0.5}}$ in flux within $X_{\mathrm{MS}_{0.5}}<0.5, \mathrm{KS}_{0.5}$ is relatively the most effective in decreasing $\gamma_{\mathrm{CuS}_{0.5}}$ among the three kinds of additives. But at $X_{\mathrm{MS}_{0.5}}>0.5, \gamma_{\mathrm{CuS}_{0.5}}$

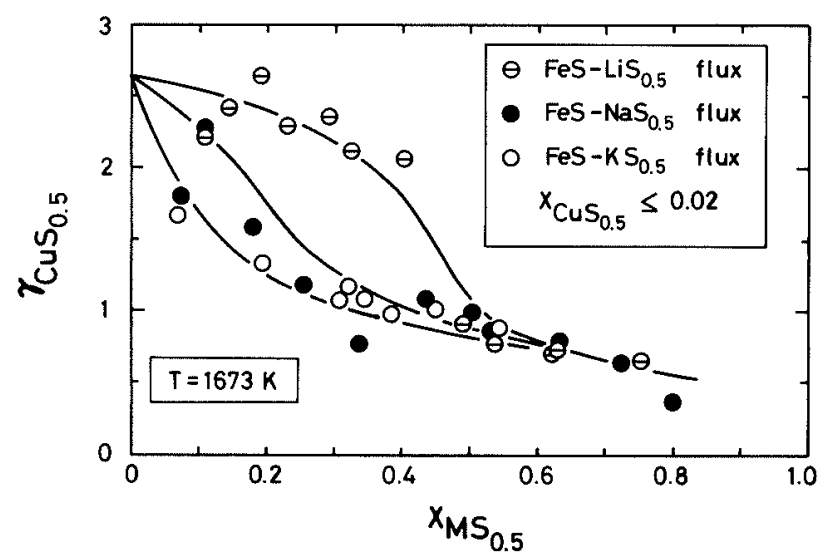

Fig. 9. Variation of $\gamma_{\mathrm{CuS}_{0.5}}$ with $\mathrm{MS}_{0.5}$ content in $\mathrm{FeS}-\mathrm{MS}_{0.5}$ fluxes.

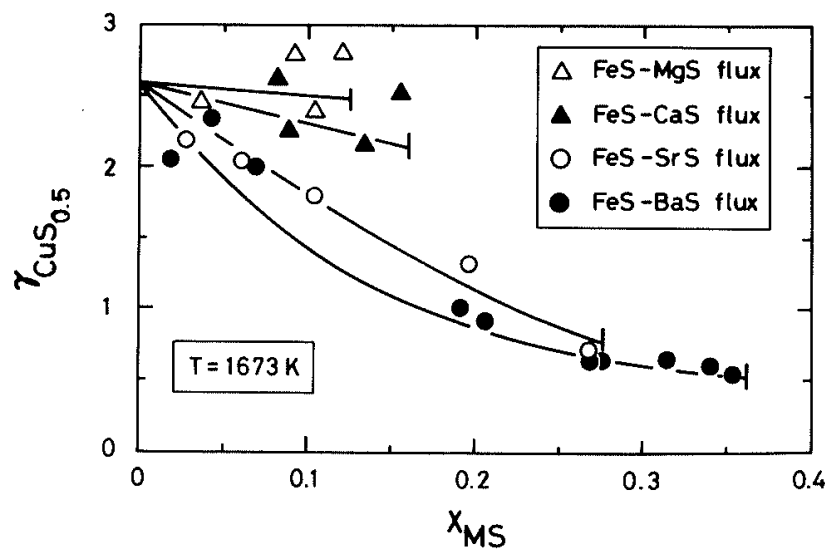

Fig. 10. Variation of $\gamma_{\mathrm{CuS}_{0,5}}$ with MS content in FeS-MS fluxes. 


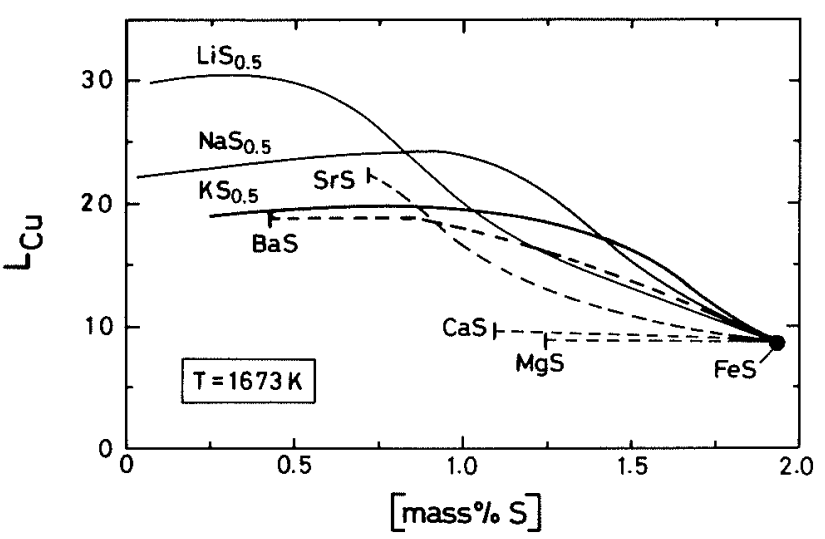

Fig. 11. Relationship between $L_{\mathrm{Cu}}$ and sulfur content in carbon saturated liquid iron equilibrated with FeS-MS 0.5 and FeS-MS fluxes.

becomes nearly equivalent for three $\mathrm{FeS}-\mathrm{MS}_{0.5}$ fluxes and tends to a constant of about 0.5 with further increasing $X_{\mathrm{MS}_{0.5^{*}}}$. Topkaya ${ }^{15)}$ has measured the activities in $\mathrm{NaS}_{0.5}-\mathrm{CuS}_{0.5}$ binary. An extrapolation from his data leads to a value of about 0.6 for $\gamma_{\text {CuS } 0.5}^{\circ}$ in $\mathrm{NaS}_{0.5}$ melt, which is very close to the result at high content of $\mathrm{MS}_{0.5}$ in the present work. It is thus suggested that $\gamma_{\mathrm{CuS}_{0.5}}$ might not be lowered further, i.e. much lower than 0.5 , by the addition of $\mathrm{MS}_{0.5}$ to molten FeS.

Figure 10 shows that the effect of $\mathrm{MgS}$ and $\mathrm{CaS}$ on the activity coefficient of $\mathrm{CuS}_{0.5}$ seems not to be significant within the investigated range, though $\gamma_{\mathrm{CuS}_{0.5}}$ tends to decrease slightly. In the case of FeS-SrS and $-\mathrm{BaS}$ fluxes which have a wider homogeneous liquid range, $\gamma_{\mathrm{CuS}_{0.5}}$ decreases notably with increasing contents of $\mathrm{SrS}$ or $\mathrm{BaS}$ so that $L_{\mathrm{Cu}}$ is increased. However, the decrease rate of $\gamma_{\mathrm{CuS}_{0.5}}$ becomes lower with the increase of $X_{\mathrm{SrS}}$ and $X_{\mathrm{BaS}}$ and, similar to that in FeS-MS 0.5 fluxes, $\gamma_{\mathrm{CuS}_{0.5}}$ tends to be a certain value at the composition close to $\mathrm{SrS}$ and $\mathrm{BaS}$ saturation. This tendency for $\gamma_{\mathrm{Cu}}$. vary suggests that the increase in the capacity of copper removal of FeS-based flux by the addition of $\mathrm{MS}_{0.5}$ and MS is limited.

\subsection{Limitation of Copper Removal by FeS-based Fluxes}

The copper distribution ratio using various fluxes and the corresponding sulfur content in iron melt are summarized in Fig. 11. In view of practical application, it is desirable to obtain a larger $L_{\mathrm{Cu}}$ and a lower sulfur content in iron melt. Therefore, the preferable condition is shown in the upper-left corner of the figure. Accordingly, the system of $\mathrm{FeS}-\mathrm{LiS}_{0.5}$, among the fluxes investigated, is the most suitable flux for this purpose.

Imai and Sano ${ }^{9,13)}$ substituted part of $\mathrm{NaS}_{0.5}$ in FeS-NaS ${ }_{0.5}$ flux by $\mathrm{KS}_{0.5}, \mathrm{LiS}_{0.5}, \mathrm{CaS}$, and $\mathrm{BaS}$ to examine their effect on $L_{\mathrm{Cu}}$. Their results indicated that $L_{\mathrm{Cu}}$ colud not be raised by these substitutions. Jimbo et al. ${ }^{10)}$ tested the addition of $\mathrm{PbS}, \mathrm{MnS}$ and $\mathrm{Al}_{2} \mathrm{~S}_{3}$ into $\mathrm{FeS}-\mathrm{NaS}_{0.5}$ flux, and reported that there was no beneficial effect on copper distribution.

Thus, it might be difficult to develop a sulfide which can drastically lower $\gamma_{\mathrm{CuS}_{0.5}}$, though information on phase diagrams of sulfides is not yet adequate. Therefore, the distribution ratio of copper by FeS-based fluxes might be limited to about 30 which can be obtained using LiS $_{0.5}$.

\section{Conclusions}

Effects of alkaline and alkaline earth metal sulfides on copper distribution between sulfide flux and $\mathrm{Fe}-\mathrm{C}_{\text {sat. }}$. melt were investigated at $1673 \mathrm{~K}$ and the following conclusions were made:

(1) The addition of alkaline metal sulfides, such as $\mathrm{K}_{2} \mathrm{~S}, \mathrm{Na}_{2} \mathrm{~S}$ and $\mathrm{Li}_{2} \mathrm{~S}$, and alkaline earth metal sulfides, $\mathrm{SrS}$ and $\mathrm{BaS}$, increase copper distribution ratio while markedly suppressing the sulfur content in iron melt. However, the increase in $L_{\mathrm{Cu}}$ is quite limited. The maximums of $L_{\mathrm{Cu}}$ are about 20,24, 30, 22 and 19 for the fluxes of $\mathrm{FeS}-\mathrm{K}_{2} \mathrm{~S},-\mathrm{Na}_{2} \mathrm{~S},-\mathrm{Li}_{2} \mathrm{~S},-\mathrm{SrS}$ and $-\mathrm{BaS}$, respectively. The main reason for the increase of $L_{\mathrm{Cu}}$ is the significant decrease of $\gamma_{\mathrm{CuS}_{0.5}}$ by the addition of these sulfides.

(2) Effects of alkaline and alkaline earth metal sulfides on the capacity of copper removal of flux are chemically the same.

(3) It is possible to remove copper by $\mathrm{FeS}-\mathrm{MS}_{0.5}$ or FeS-MS flux while controlling sulfur content below 0.1 mass $\%$. The expected copper distribution ratio is about 20 to 30 .

\section{Acknowledgments}

The authors are indebted to Dr. S. Anezaki of Sumitomo Metal Industries, Ltd. and Dr. F. Ishii of Tohoku University for their helpful comments and suggestions. Thanks are due to Mr. S. Kitagawa and Mr. Y. Ohtaki, former undergraduate students of Tohoku University for their direct assistance. Thanks are also extended to Mr. T. Mototsu, Tohoku University. This work was financially supported by Grants-in-Aid, for Encouragement of Young Scientists in 1988 and for General Scientific Research (C) in 1989 and 1990 from The Ministry of Education, Science and Culture of Japan.

\section{REFERENCES}

1) P. V. Riboud and M. Bourge: Ironmaking Steelmaking, 12 (1985), 285.

2) H. Katayama: The 122nd \& 123rd Nishiyama Memorial Seminar, ISIJ, Tokyo, (1988), 91.

3) F. C. Langenberg, R. W. Lindsay and D. P. Robertson: Blast Furnace and Steel Plant, 43 (1955), 1142.

4) H. V. Maker and B. W. Dunning: J. Met., 21 (1969), 19.

5) Y. A. Topkaya and W-K. Lu: Int. Symp. on Metal-Slag-Gas Reaction and Processes, The Electrochem. Soc., Princeton, N.J. (1975), 111.

6) X. Liu and J. H. E. Jeffes: Ironmaking Steelmaking, 12 (1985), 293.

7) T. Okazaki and D. G. C. Robertson: Ironmaking Steelmaking, 12 (1985), 295.

8) R. Matsuo and S. Inui: Tetsu-to-Hagané, 73 (1987), S233.

9) T. Imai and N. Sano: Trans. Iron Steel Inst. Jpn., 28 (1988), 999.

10) I. Jimbo, M. S. Sulsky and R. J. Fruehan: Proc. W. O. Philbrook Mem. Symp., ISS-AIME, Warrendale, PA, (1988), 133.

11) C. Wang, J. Hirama, T. Nagasaka and S. Ban-ya: ISIJ Int., 31 (1991), 1292.

12) C. Wang, T. Nagasaka, M. Hino and S. Ban-ya: ISIJ Int., 31 (1991), 1300.

13) T. Imai: Master of Eng. Thesis, The University of Tokyo, (1987)

14) G. V. Samsonov and S. V. Drozdova: Handbook of Sulfides, Japan-Soviet Communication Soc., Tokyo, (1972). 
15) Y. A. Topkaya: Ph. D. Thesis, McMaster Univ, Hamilton, Ontario,Canada, (1974).

16) V. T. Heumann: Arch. Eisenhüttenwes., 15 (1942), 557.

17) M. Iwase: The 122nd \& 123rd Nishiyama Memorial Seminar, ISIJ, Tokyo, (1988), 59.

\section{Appendix. Solubilities of Alkaline Earth Metal Sulfides in Molten FeS}

The activity of sulfur in iron melt is determined by the relation shown in Eq. (6), i.e. the equilibrium between sulfide and iron phases. $a_{\mathrm{Fes}}$ will remain constant if the flux is saturated with solid MS. It is known that $a_{\mathrm{Fe}}$ in the present work is almost constant, ${ }^{11}$ ) so a constant $a_{\mathrm{FeS}}$ would assure a constant $a_{\mathrm{S}}$ at MS saturation. Sulfur content in $\mathrm{Fe}-\mathrm{C}_{\text {Sat. }}$ melt will therefore be constant at MS saturation.

Figure 6 shows that, as expected, the sulfur content tends to be constant beyond a certain concentration of MS in fluxes considered to be saturated with MS. It has been observed after the experiments that an unmelted phase existed in those samples considered to be MS saturation. Accordingly, the solubility of MS in molten
Table 2. Solubility of MgS, CaS, $\mathrm{SrS}$ or BaS in liquid FeS at $1673 \mathrm{~K}$.

\begin{tabular}{ccccc}
\hline & $\mathrm{MgS}$ & $\mathrm{CaS}$ & $\mathrm{SrS}$ & $\mathrm{BaS}$ \\
\hline Solubility & 0.125 & 0.16 & 0.275 & 0.36 \\
\hline
\end{tabular}

Solubilities are in mole fraction.

FeS was estimated based on the result in Fig. 6, and these estimated solubility are given in Table 2. According to the phase diagram for $\mathrm{FeS}-\mathrm{CaS}$ system suggested by Heumann, ${ }^{16)}$ the solubility of $\mathrm{CaS}$ in $\mathrm{FeS}$ approximates 0.23 mole fraction at $1673 \mathrm{~K}$, which is somewhat larger than that estimated in the present work. There are few data available on the solubilities of the other MS in molten FeS. It is seen from Table 2 that the solubility of MS in molten FeS is larger in the order of $\mathrm{MgS}, \mathrm{CaS}$, $\mathrm{SrS}$ and BaS. This order is coincident with that of solubilities of alkaline earth metal oxides, $\mathrm{MO}$, in $\mathrm{FeO} .{ }^{17)}$

(Originally published in Tetsu-to-Hagané, 77 (1991), 644, in Japanese) 